\title{
Detection of Quantitative Trait Loci for White-back and Basal-white Kernels under High Temperature Stress in japonica Rice Varieties
}

\author{
Asako Kobayashi*1), Bao Genliang ${ }^{1,2)}$, Ye Shenghai ${ }^{1,2)}$ and Katsura Tomita ${ }^{1)}$ \\ 1) Fukui Agricultural Experiment Station, 52-21 Ryomachi, Fukui 918-8215, Japan \\ 2) Present address: Zhejiang Academy of Agricultural Sciences, 198 Shiqiao Road, Hangzhou 310021, China
}

\begin{abstract}
Several quantitative trait loci (QTLs) associated with the apparent quality of brown rice were identified. QTL analysis was carried out using $\mathrm{F}_{2}$ and $\mathrm{F}_{3}$ populations derived from a cross between two japonica varieties, Hana-echizen (high quality of brown rice) and Niigatawase (low quality with numerous white-back and basalwhite kernels). $F_{2}$ individuals were grown in paddy fields in 2003, and $F_{3}$ lines were grown in paddy fields and in a greenhouse to expose them to high temperature stress during the ripening period in 2004. Apparent quality of brown rice was evaluated based on the percentage of white-back and basal-white kernels. Two putative QTLs associated with white-back kernels in the $\mathrm{F}_{2}$ population grown under low temperature conditions in paddy fields in 2003 were identified on chromosomes 3 and 6. The closest SSR markers were RM4512 and RM3034, respectively. One putative QTL associated with basal-white kernels in the $\mathrm{F}_{2}$ population was identified on chromosome 6. The closest marker was RM3034. Two putative QTLs associated with whiteback kernels in the $\mathrm{F}_{3}$ population grown under high temperature conditions in paddy fields in 2004 were identified on chromosomes 4 and 6. The closest SSR markers were RM3288 and RM3034, respectively. One putative QTL associated with white-back plus basal-white kernels in the $F_{3}$ population grown under high temperature stress in the greenhouse was identified on chromosome 6. The closest marker was RM3034. The QTLs identified near RM3034 on the short arm of chromosome 6 contributed most to the apparent quality of brown rice. The QTLs identified near RM4512 and RM3288 which also affected the apparent quality of brown rice, were detected in either the $F_{2}$ or $F_{3}$ population. The QTLs identified in the present study should be useful for marker-assisted selection to breed varieties with a high apparent quality of brown rice, especially varieties with tolerance to kernel damage due to high temperature stress during the ripening period.
\end{abstract}

Key Words: QTL, apparent quality of brown rice, white-back kernels, basal-white kernels, high temperature stress.

\section{Introduction}

Recently serious deterioration of the apparent quality of brown rice has been reported in many areas in Japan (Arisaka 2001, Terashima et al. 2001, Terashima 2003, Omoteno et al. 2003, Tsukimori 2003).

In Fukui prefecture, from 1974 to 1998,80 to $95 \%$ of brown rice had been ranked as first grade rice in the inspection standard for non-glutinous paddy brown rice described in the report of Hoshikawa (1989). However, from 1999 onward, the percentage of brown rice ranked as first grade sometimes fell below $70 \%$, especially, it decresed to 69 and $62 \%$ in 1999 and 2002, respectively. The summer of these two years was very hot. The average temperature in July and August in 1999 and 2002 was $28.8^{\circ} \mathrm{C}$ and $28.5^{\circ} \mathrm{C}$, respectively, whereas that in a normal year, $26.8^{\circ} \mathrm{C}$.

Fukui prefecture is located at the southern end of the

Communicated by Ahn Sang-Nag

Received May 30, 2006. Accepted December 13, 2006.

*Corresponding author (e-mail: asako_kobayashi@fklab.fukui.fukui.jp)
Hokuriku region, which is characterized by high temperatures during the ripening period. This region is suitable for studies and breeding programs for tolerance to kernel damage due to high temperature during the ripening period. Nishimura et al. (2000) reported that many varieties derived from Koshihikari, which was bred in Fukui, displayed such tolerance. In general, early maturing varieties are susceptible to kernel damage due to high temperature stress during the ripening period. However, several early maturing varieties which are tolerant to high temperatures during the ripening period were bred in the Hokuriku region, such as Hanaechizen (Horiuchi et al. 1992), Koshi-ibuki (Hoshi et al. 2002) and Ten-takaku (Yamaguchi et al. 2005).

It was suggested that high temperatures during the ripening period affected the apparent quality of brown rice (Konno et al. 1991, Morita 2000, Terashima et al. 2001). Furthermore, with the progression of global warming, it is possible that temperatures during the ripening period could become higher. Therefore, tolerance to kernel damage due to high temperature stress during the ripening period has become an important objective in rice breeding in Japan. 
Nagato and Ebata (1965) and Iida et al. (1997) reported that a large number of white-back and basal-white kernels occurred due to high temperature. White-back kernels contain a few layers of starch cells distributed along the vascular bundles on the dorsal side of a rice grain and look white and opaque due to incomplete filling. In the case of basal-white kernels, the basal portion of a grain is white and opaque (Taira 1995). Nagato and Ebata (1965) and Iida et al. (2002) indicated that the percentage of white-back kernels was the most appropriate index of tolerance to kernel damage due to high temperature stress during the ripening period, because they occurred only under high temperature conditions. Clear varietal differences were reported in the occurrence of white-back kernels due to high temperature (Nagato et al. 1961, Komaki et al. 2000, Nishimura et al. 2000).

Nishimura et al. (2000) and Iida and Tabata (2003) indicated that the tolerance to kernel damage due to high temperature stress during the ripening period was genetically controlled, and Tabata et al. (2005) performed a genetic analysis of the occurrence of white-back and basal-white kernels associated with high temperature during the ripening period.

He et al. (1999), Terao et al. (2004) and Ebitani et al. (2005) reported the presence of QTLs associated with the apparent quality of brown rice. These studies were conducted using a population derived from a cross between a japonica variety and an indica variety. It is preferable to use QTL information about apparent quality of brown rice using a population derived from a cross between japonica varieties for the breeding of japonica varieties, because of the differences in the shape and size of brown rice between japonica and indica varieties. Shirasawa et al. (2006) reported that several QTLs were associated with white-back kernels under high temperature stress using a recombinant inbred line population derived from a cross between two japonica varieties. However, there are very few studies in which only japonica varieties were used, because the construction of a genetic map is more difficult using two japonica varieties due to the rather low polymorphisms, compared with that of a genetic map using indica and japonica varieties.

We investigated the apparent quality of brown rice and identified several QTLs, using a population derived from a cross between two japonica varieties, Hana-echizen and Niigatawase (Bao et al. 2004, Ye et al. 2006). In the present study, we conducted a QTL analysis on the occurrence of white-back and basal-white kernels using $F_{2}$ and $F_{3}$ populations.

\section{Materials and Methods}

\section{Plant materials}

A cross was made between Hana-echizen and Niigatawase that are both early maturing varieties in which the apparent quality of brown rice is considerably different. The apparent quality of brown rice in Hana-echizen is high (Horiuchi et al. 1992, Inoue 1999), whereas, that in Niigata- wase is low because of the presence of numerous white-back and basal-white kernels (Sasaki et al. 1983, Hoshi et al. 2002, Nagahata and Yamamoto 2005). Niigatawase showed a high percentage of white-back and basal-white kernels not only upon hot water irrigation during the ripening period but also under normal air temperature conditions in paddy fields (Kasaneyama et al. 1999).

A total of $180 \mathrm{~F}_{2}$ individuals from the cross and the parents were transplanted to paddy fields in Fukui in 2003, and cultivated according to standard practices. Leaves were individually sampled from each $F_{2}$ plant to isolate genomic DNA. A total of $180 \mathrm{~F}_{3}$ families derived from the $\mathrm{F}_{2}$ individuals and the parents were transplanted to paddy fields and to a greenhouse in 2004, and cultivated according to standard practices. Air temperature in the greenhouse was controlled by ventilation when the temperature exceeded $35^{\circ} \mathrm{C}$. Days to heading were calculated from the time of transplanting.

Seeds of $180 \mathrm{~F}_{2}$ individuals and seeds of 10 plants from each of the $180 \mathrm{~F}_{3}$ lines and the parents were harvested 30 days after heading, air-dried and hulled to evaluate the apparent quality of brown rice.

\section{Evaluation of kernel and other traits}

Five-hundred grains were sampled from each plant, and the number of white-back and basal-white kernels was counted according to the criterion adopted by The Ministry of Agriculture, Forestry and Fisheries of Japan (http://www. kanbou.maff.go.jp/www/gichou/hitemp/hannteikizyun/ PAGE001.HTM). When the opaque portion of the dorsal side was longer than $2 / 3$ of the kernel length and wider than $1 / 3$ of the kernel width, the kernel was classified into whiteback. When the opaque portion was distributed in the basal portion and the size was larger than $1 / 5$ of the kernel size, the kernel was classified into basal-white. In the $F_{3}$ lines grown in the greenhouse in 2004, since numerous whiteback and basal-white kernels occurred simultaneously, we could not distinguish them. Therefore, the apparent quality was expressed as the percentage of the sum of white-back plus basal-white kernels. Phenotypic values of the apparent quality of brown rice were expressed as the percentage of white-back or basal-white kernels after arc sine transformation to normalize the variance.

Nagato and Ebata (1965) reported that white-back and basal-white kernels occurred due to high temperature during the ripening period, which impeded the accumulation of starch. Decrease in final grain weight at high temperatures was attributed to the early decline of the sink activity of caryopses (Kumura 1995). Since the sink size may be closely related to kernel traits, we measured the sink size, namely the panicle weight and one-thousand kernel weight in the $\mathrm{F}_{2}$ generation. Panicle weight was measured as grain yield per plant. Panicle weight and one-thousand kernel weight of the parents (Hana-echizen and Niigatawase) were calculated based on the average value of 10 plants. 


\section{DNA isolation and QTL analysis}

Genomic DNA was extracted from the leaves using 100 $\mathrm{mM}$ Tris- $\mathrm{HCl}$ (pH 8.0) buffer containing $10 \mathrm{mM}$ EDTA and $1 \mathrm{M} \mathrm{KCl}$, according to the method of Monna et al. (2002). PCR was performed in $10 \mu \mathrm{l}$ volume of a reaction mixture, containing $10 \mathrm{ng}$ of genomic DNA, $10 \mathrm{mM}$ Tris- $\mathrm{HCl}$ ( $\mathrm{pH}$ 8.0), $50 \mathrm{mM} \mathrm{KCl}, 4 \mu \mathrm{M}$ of each forward and reverse primer, $1.5 \mathrm{mM} \mathrm{MgCl}_{2}, 2 \mathrm{mM}$ of dNTPs and 0.25 unit of AmpliTaq Gold DNA polymerase (Applied Biosystems). The mixture was initially heated at $95^{\circ} \mathrm{C}$ for $10 \mathrm{~min}$, followed by $35 \mathrm{cy}$ cles at $94^{\circ} \mathrm{C}$ for $30 \mathrm{sec}, 55^{\circ} \mathrm{C}$ for $1 \mathrm{~min}$ and $72^{\circ} \mathrm{C}$ for $2 \mathrm{~min}$ on a PCR system (iCycler Thermal Cycler System, BIO RAD). PCR products were fractionated on a $2.0 \%$ agarose TBE gel. After EtBr dyeing, the PCR products were visualized using an UV illuminator and polymorphisms were detected.

A total of 407 simple sequence repeat (SSR) markers were screened to identify polymorphisms between Hanaechizen and Niigatawase. Then a genetic map was constructed using the polymorphic SSR markers with MAPMAKER/ EXP 3.0 (Lander et al. 1987). The Kosambi mapping function was used to estimate marker distances.

Composite interval mapping (CIM) was performed using Windows QTL Cartographer 2.5 (Wang et al. 2006) with the forward and backward regression model (model 6). To control the genetic background, 5 markers and $10 \mathrm{cM}$ window size were used for CIM. The significance level of the experiment-wise LOD threshold was determined by computing 1000 permutations as implemented by the software. The LOD peaks at significant QTL intervals were considered to correspond to the putative QTL locations on the linkage map. The percentage of phenotypic variation explained by a QTL for traits and the additive effect were also estimated using the software. In addition, we performed single marker analysis for solitary markers which were not linked to any linkage group. This analysis fitted the data to the simple linear regression model to determine whether the marker was linked to a QTL.

\section{Results}

Days to heading and temperature during the ripening period The average days to heading of Hana-echizen and Niigatawase in paddy fields were 56 and 58 days, respectively in 2003, and 59 and 60 days, respectively in 2004. The average days to heading for Hana-echizen and Niigatawase which were grown in the greenhouse in 2004 were both 60 days. Days to heading of the $\mathrm{F}_{2}$ population in paddy fields ranged from 54 to 61 days, and those of the $F_{3}$ population in paddy fields and in the greenhouse ranged from 54 to 66 days and from 57 to 64 days, respectively (Table 1 and Fig. 1A, B).

Average temperatures during the ripening period, namely 30 days after heading, were $24.9^{\circ} \mathrm{C}, 27.2^{\circ} \mathrm{C}$ and $31.2^{\circ} \mathrm{C}$, in paddy fields in 2003,2004 and in the greenhouse in 2004, respectively. The temperature in the summer of 2003 was relatively low compared to that in a normal year in Fukui $\left(26.7^{\circ} \mathrm{C}\right)$. On the other hand, in the paddy fields in 2004, the temperature was considered to be high. Indeed, based on the studies of Terashima (2003) on the apparent quality of brown rice, when the average temperature after heading exceeds $27^{\circ} \mathrm{C}$, the apparent quality of brown rice is likely to deteriorate. The greenhouse condition was considered to correspond to strong high temperature stress.

Variation in the percentage of white-back and basal-white kernels in the parents, $F_{2}$ and $F_{3}$ populations

The percentage of white-back and basal-white kernels in Hana-echizen and Niigatawase is listed in Table 1. In general, the apparent quality of brown rice in Hana-echizen was much higher than that in Niigatawase. All the differences in the percentage of white-back and basal-white kernels between Hana-echizen and Niigatawase were significant. Especially, Hana-echizen did not exhibit white-back kernels under paddy field conditions either in 2003 or 2004, and very few basal-white kernels occurred under paddy fields conditions in 2003 (low temperature summer). The values of

Table 1. Kernel and other traits of Hana-echizen, Niigatawase, $F_{2}$ population cultivated in paddy fields in 2003, and $F_{3}$ population cultivated in paddy fields and greenhouse in 2004

\begin{tabular}{|c|c|c|c|c|c|c|c|c|c|c|c|c|}
\hline \multirow{3}{*}{ Traits } & \multirow{3}{*}{ Condition } & & \multicolumn{5}{|c|}{2003} & \multicolumn{5}{|c|}{2004} \\
\hline & & & \multirow{2}{*}{$\begin{array}{l}\text { Hana- } \\
\text { echizen }^{1)}\end{array}$} & \multirow{2}{*}{$\begin{array}{l}\text { Niigata- } \\
\text { wase }^{1)}\end{array}$} & \multicolumn{3}{|c|}{$\mathrm{F}_{2}$} & \multirow{2}{*}{$\begin{array}{c}\text { Hana- } \\
\text { echizen }{ }^{1)}\end{array}$} & \multirow{2}{*}{$\begin{array}{l}\text { Niigata- } \\
\text { wase }^{1)}\end{array}$} & \multicolumn{3}{|c|}{$\mathrm{F}_{3}$} \\
\hline & & & & & Ave. & Max. & Min. & & & Ave. & Max. & Min. \\
\hline White-back kernels & Paddy fields & $(\%)$ & 0.0 & $4.8 * 2)$ & 6 & 38 & 0 & 0.0 & $15.4 * *$ & 11 & 48 & 1 \\
\hline Basal-white kernels & Paddy fields & $(\%)$ & 0.7 & $17.4 * * 2)$ & 8 & 44 & 0 & 7.8 & $34.8 * *$ & 20 & 39 & 0 \\
\hline $\begin{array}{l}\text { White-back plus } \\
\text { basal-white kernels }\end{array}$ & Greenhouse & $(\%)$ & - & - & - & - & - & 51.6 & $82.6 * *$ & 74 & 100 & 32 \\
\hline \multirow[t]{2}{*}{ Days to heading } & Paddy fields & (days) & 56 & $58 \mathrm{~ns}^{2)}$ & 57 & 61 & 54 & 59 & $60 \mathrm{~ns}$ & 60 & 66 & 54 \\
\hline & Greenhouse & (days) & - & - & - & - & - & 60 & $60 \mathrm{~ns}$ & 61 & 64 & 57 \\
\hline \multirow{2}{*}{$\begin{array}{l}\text { Panicle weight } \\
\text { One-thousand kernel } \\
\text { weight }\end{array}$} & Paddy fields & (g/plant) & 28.7 & $24.5^{* *}$ & 28.7 & 39.8 & 17.1 & - & - & - & - & - \\
\hline & Paddy fields & (g) & 20.6 & $18.5 * *$ & 19.9 & 21.8 & 18.2 & - & - & - & - & - \\
\hline
\end{tabular}

1) Value for Hana-echizen and Niigatawase is the average of 10 plants.

2) $* * *$ and ns: t-test significant at $1 \%, 5 \%$ levels and not significant, respectively. 

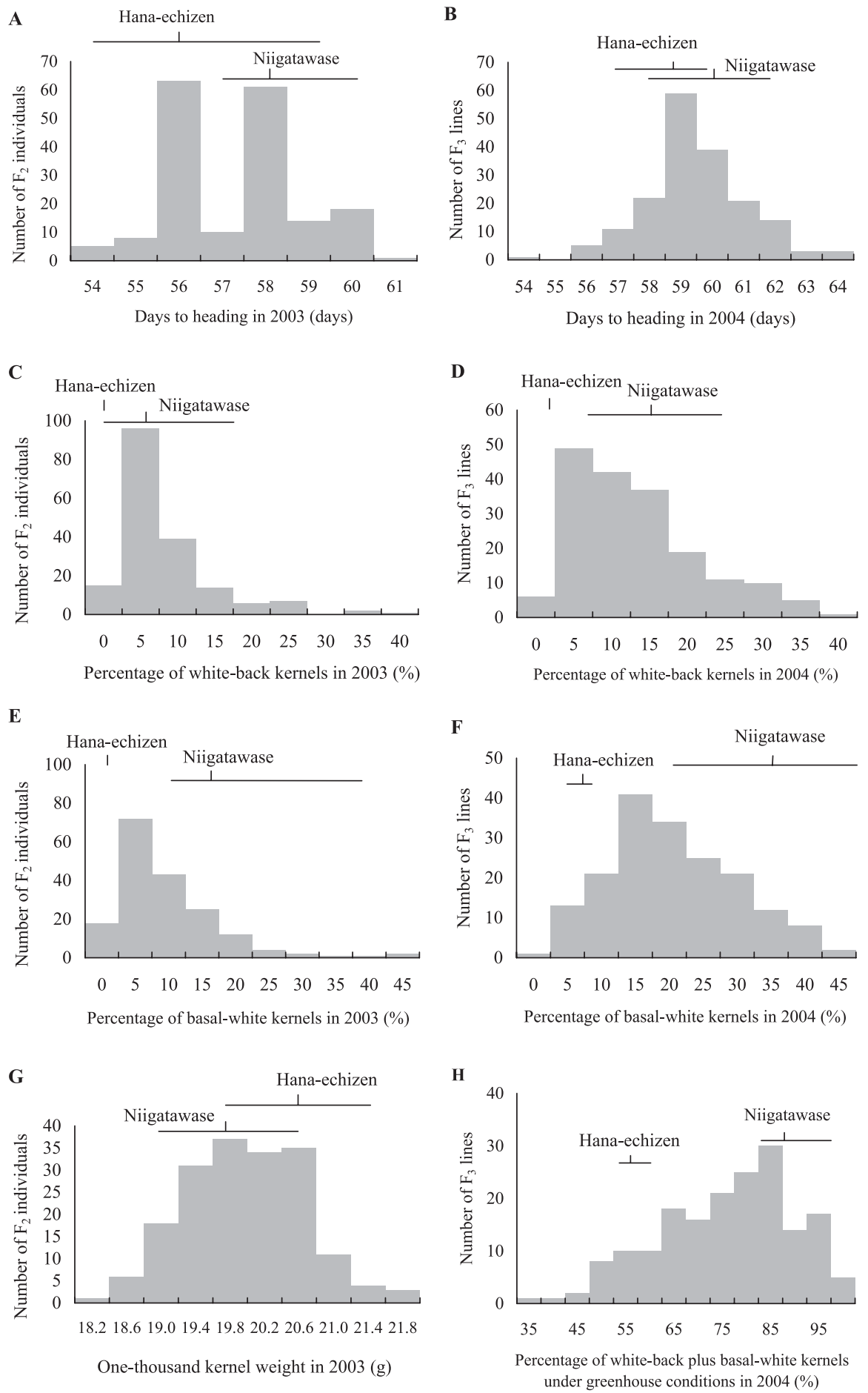

Fig. 1. Frequency distribution of days to heading, percentage of white-back and basal-white kernels and one-thousand kernel weight in the $\mathrm{F}_{2}$ and $\mathrm{F}_{3}$ populations. Bars indicate the average and range of the parent plants.

one-thousand kernel weight and panicle weight of Hanaechizen were significantly higher than those of Niigatawase, as shown in Table 1.

Frequency distribution of the percentage of white-back and basal-white kernels in the $\mathrm{F}_{2}$ and $\mathrm{F}_{3}$ populations was mostly continuous (Fig. 1). As indicated in Figure 1, some $\mathrm{F}_{2}$ individuals and some $\mathrm{F}_{3}$ lines showed a higher percentage of white-back kernels than Niigatawase, the parent with the lowest apparent quality of brown rice (Fig. 1C and D). On the other hand, the percentage of basal-white kernels in the progenies was distributed mostly between that of their parents (Fig. 1E and F). The distribution of the percentage of 
white-back plus basal-white kernels under the greenhouse conditions was not symmetrical: the skewness was -2.16 , leaning to the average value recorded in Niigatawase (Fig. $1 \mathrm{H})$. The values of one-thousand kernel weight (Fig. 1G) and panicle weight (not in the figure) were distributed mostly between those of the parents.

Correlation analysis was conducted among the traits (Table 2). The percentage of white-back kernels and basalwhite kernels was positively and highly correlated in both the $\mathrm{F}_{2}$ and $\mathrm{F}_{3}$ populations. The correlation of the occurrence of white-back and basal-white kernels between the $F_{2}$ and $F_{3}$ populations is shown in Figure 2. There was a positive correlation between them. As shown in Table 2, there was no relationship between the days to heading and the percentage of white-back or basal-white kernels in the $F_{2}$ population. However, in the $\mathrm{F}_{3}$ population, the percentage of basal-white kernels was positively correlated with the days to heading. The values of one-thousand kernel weight and the percentage of white-back or basal-white kernels in the $\mathrm{F}_{2}$ population were positively correlated, while the values of panicle weight and the percentage of white-back or basal-white kernels in the $\mathrm{F}_{2}$ population were not significantly related.

\section{Genetic map construction}

Among the 407 SSR markers screened, 64 (15.7\%) showed polymorphisms between Hana-echizen and Niigatawase. These markers were classified in 13 linkage groups by linkage analysis, except for 8 markers which did not belong to any linkage group. The information about these 8 solitary markers is listed in Figure 3. Finally, the genetic map was constructed using 56 SSR markers on chromosomes 1, 2, 3, 4, 5, 6, 7, 8, 10 and 11 (Fig. 3).

\section{QTL identification}

The analysis by CIM revealed the presence of QTLs associated with white-back and basal-white kernels and onethousand kernel weight (Table 3 and Fig. 3). The threshold values for $\mathrm{P}<0.05$ ranged from 3.64 to 4.38 . For all the QTLs associated with white-back, basal-white and whiteback plus basal-white kernels, the Hana-echizen alleles decreased the ratio of damaged kernels.

Table 4 shows the solitary markers which were linked to a QTL by single marker analysis.

\section{White-back kernels}

Significant threshold LOD values $(\mathrm{P}<0.05)$ of whiteback kernels under low temperature conditions in paddy

Table 2. Correlation matrix between measured traits of $\mathrm{F}_{2}$ individuals and $\mathrm{F}_{3}$ lines

\begin{tabular}{|c|c|c|c|c|c|c|c|c|c|}
\hline Traits & $\mathrm{Dh} \mathrm{F}_{2}$ & $\mathrm{Dh} \mathrm{F}_{3}$ & $\mathrm{~Wb} \mathrm{~F}_{2}$ & $\mathrm{Bw} \mathrm{F}_{2}$ & $\mathrm{~Wb} \mathrm{~F}_{3}$ & $\mathrm{Bw} \mathrm{F}_{3}$ & Gh & $\mathrm{Tw} \mathrm{F}_{2}$ & $\mathrm{Pw} \mathrm{F}$ \\
\hline Days to heading of $F_{2}\left(\mathrm{Dh} \mathrm{F}_{2}\right)$ & 1.00 & & & & & & & & \\
\hline Days to heading of $F_{3}\left(\mathrm{Dh} \mathrm{F}_{3}\right)$ & $0.37 * * 2)$ & 1.00 & & & & & & & \\
\hline White-back kernels of $\mathrm{F}_{2}\left(\mathrm{~Wb} \mathrm{~F}_{2}\right)$ & 0.08 & -0.07 & 1.00 & & & & & & \\
\hline Basal-white kernels of $F_{2}\left(B w F_{2}\right)$ & 0.08 & -0.02 & $0.60 * *$ & 1.00 & & & & & \\
\hline White-back kernels of $F_{3}\left(\mathrm{~Wb} \mathrm{~F}_{3}\right)$ & -0.02 & -0.13 & $0.46^{* *}$ & $0.38 * *$ & 1.00 & & & & \\
\hline Basal-white kernels of $\mathrm{F}_{3}\left(\mathrm{Bw} \mathrm{F}_{3}\right)$ & $0.17 * 2)$ & $0.20 * *$ & $0.32 * *$ & $0.32 * *$ & $0.52 * *$ & 1.00 & & & \\
\hline $\begin{array}{l}\text { White-back plus basal-white kernels } \\
\text { in Greenhouse }{ }^{1)}(\mathrm{Gh})\end{array}$ & $0.14^{*}$ & 0.06 & $0.24 * *$ & $0.17 *$ & $0.36^{* *}$ & $0.39^{* *}$ & 1.00 & & \\
\hline $\begin{array}{l}\text { One-thousand kernel weight of } \mathrm{F}_{2} \\
\left(\mathrm{Tw} \mathrm{F}_{2}\right)\end{array}$ & $-0.29 * *$ & -0.09 & $0.27 * *$ & $0.24 * *$ & $0.27 * *$ & $0.23 * *$ & $0.22 * *$ & 1.00 & \\
\hline Panicle weight of $\mathrm{F}_{2}\left(\mathrm{Pw} \mathrm{F}_{2}\right)$ & -0.11 & 0.01 & 0.02 & 0.07 & -0.01 & -0.09 & -0.03 & $0.16^{*}$ & 1.00 \\
\hline
\end{tabular}

1) White-back plus basal-white kernels occurred under high temperature stress in the greenhouse in the $\mathrm{F}_{3}$ population.

2) ** and *: significant at $1 \%$ and $5 \%$ levels, respectively.
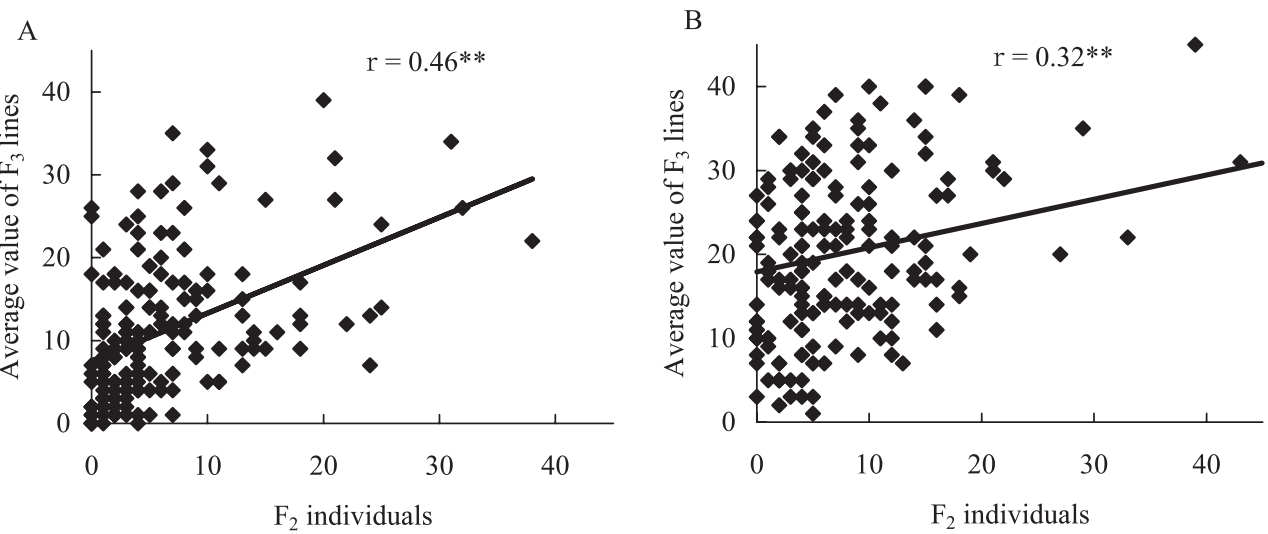

Fig. 2. Correlation of the percentage of white-back (A) and basal-white (B) kernels between $\mathrm{F}_{2}$ individuals and average value of $\mathrm{F}_{3}$ lines. 


\section{Chr.1 Chr.2 Chr.3 Chr.4 Chr.5}

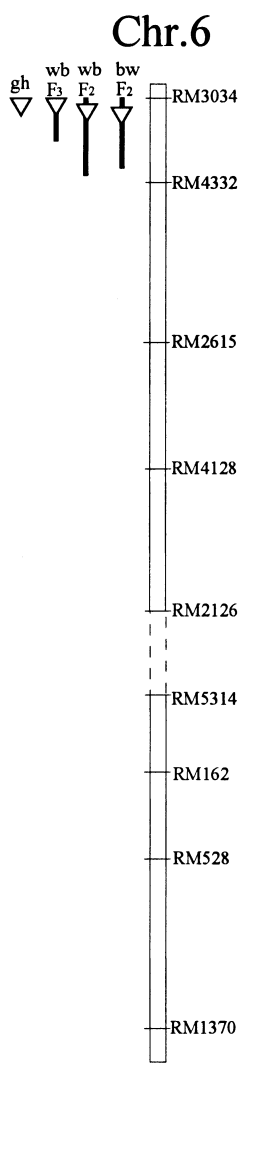

Chr.7 Chr.8

Chr.10

Chr.11
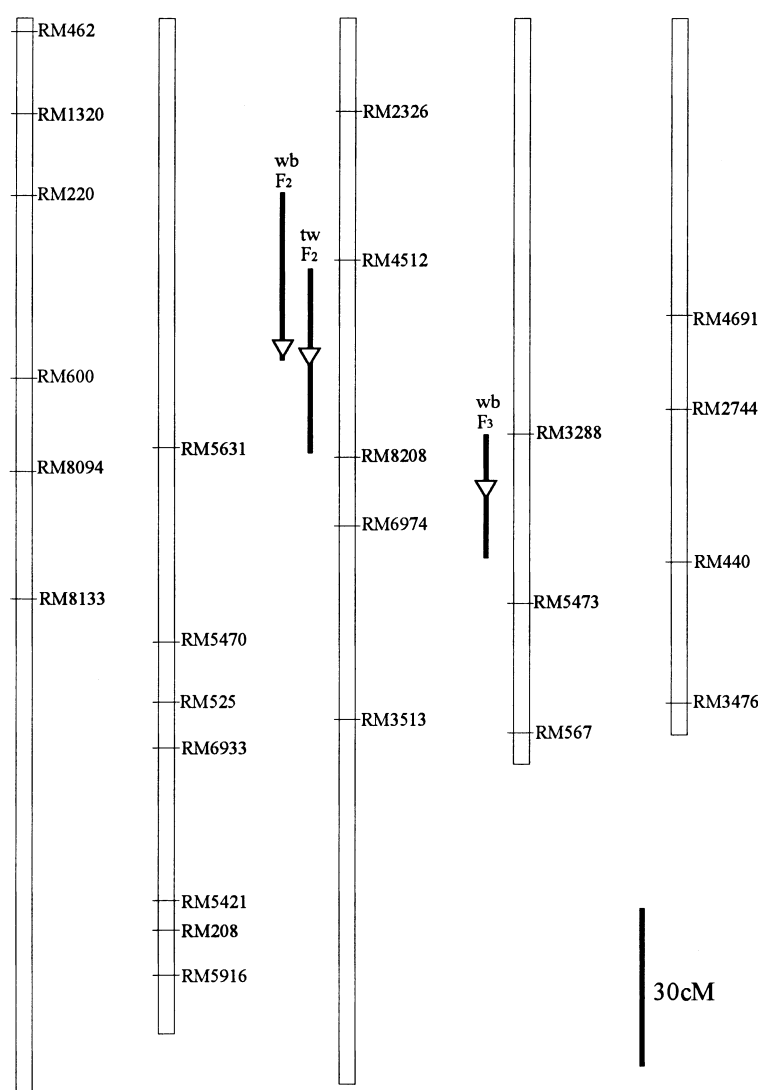
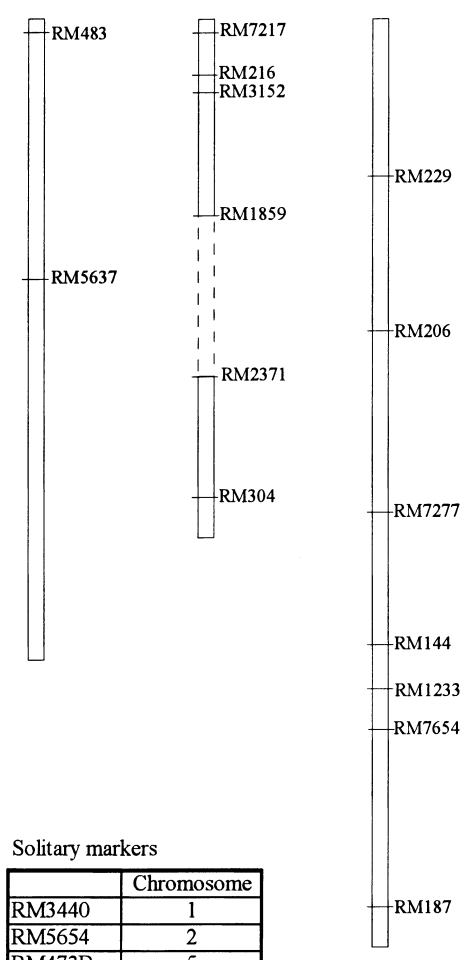

Fig.3. Linkage map and positions of putative QTLs associated with white-back and basal-white kernels and one-thousand kernel weight, and solitary markers which were not linked to any linkage group. Bars on the left side of the chromosomes indicate 1-LOD likelihood intervals, and the triangles indicate the position of the peak LOD in the interval. wb: white-back kernels, bw: basal-white kernels, gh: white-back plus basal-white kernels under greenhouse conditions, tw: one-thousand kernel weight, $F_{2}$ : traits measured in the $F_{2}$ population in 2003, $\mathrm{F}_{3}$ : traits measured in the $\mathrm{F}_{3}$ population in 2004.

Table 3. QTLs of kernel and other traits detected by composite interval mapping

\begin{tabular}{|c|c|c|c|c|c|c|c|c|}
\hline Year & Population & Traits & Chr. & $\mathrm{CML}^{1)}$ & LOD & $\mathrm{AE}^{2)}$ & $\mathrm{PVE}^{3)}$ & Threshold ${ }^{4)}$ \\
\hline \multirow[t]{4}{*}{2003} & \multirow[t]{4}{*}{$\mathrm{F}_{2}$} & White-back kernels & 3 & RM4512 & 4.60 & -0.73 & 25.9 & \multirow[t]{2}{*}{3.93} \\
\hline & & & 6 & RM3034 & 6.80 & -0.84 & 31.2 & \\
\hline & & Basal-white kernels & 6 & RM3034 & 8.08 & -1.58 & 14.1 & 4.02 \\
\hline & & One-thousand kernel weight & 3 & RM4512 & 4.98 & -0.17 & 12.3 & 4.09 \\
\hline \multirow[t]{3}{*}{2004} & \multirow[t]{3}{*}{$\mathrm{F}_{3}$} & White-back kernels & 4 & RM3288 & 4.36 & -0.53 & 15.2 & \multirow[t]{2}{*}{3.96} \\
\hline & & & 6 & RM3034 & 13.39 & -1.14 & 59.6 & \\
\hline & & $\begin{array}{l}\text { White-back plus basal- } \\
\text { white kernels in Greenhouse }\end{array}$ & 6 & RM3034 & 7.80 & -0.19 & 75.1 & 3.64 \\
\hline
\end{tabular}

1) Closest marker locus of putative QTLs.

2) Additive effects ( $1 / 2$ weight) of Hana-echizen allele. Numbers expressed in italics indicate additive effects based on arc sine transformation of the percentage of white-back or basal-white kernels.

3) Percentage of phenotypic variation explained by each QTL.

4) Significant threshold LOD value $(\mathrm{P}<0.05)$ determined by computing 1000 permutations.

fields in the $\mathrm{F}_{2}$ population (2003) and under high temperature conditions in paddy fields condition in the $\mathrm{F}_{3}$ population (2004) were 3.93 and 3.96, respectively. Two QTLs for white-back kernels in the $\mathrm{F}_{2}$ population were detected on chromosomes 3 and 6. The closest markers to the QTLs were RM4512 (chromosome 3) and RM3034 (chromosome 6), 
Table 4. Markers linked to a QTL by a single marker analysis

\begin{tabular}{|c|c|c|c|c|c|c|}
\hline Year & Population & Traits & Chr. & Marker & Significance ${ }^{1)}$ & $\mathrm{AE}^{2)}$ \\
\hline \multirow[t]{3}{*}{2003} & \multirow[t]{3}{*}{$\mathrm{F}_{2}$} & White-back kernels & 11 & RM552 & $*$ & -0.21 \\
\hline & & Basal-white kernels & 11 & RM552 & $*$ & -0.19 \\
\hline & & Days to heading & 12 & RM2197 & $*$ & 0.35 \\
\hline \multirow[t]{5}{*}{2004} & \multirow[t]{5}{*}{$\mathrm{F}_{3}$} & White-back kernels & 1 & RM3440 & $*$ & 0.26 \\
\hline & & & 2 & RM5654 & $*$ & -0.21 \\
\hline & & Basal-white kernels & 12 & RM2197 & $* *$ & 0.15 \\
\hline & & $\begin{array}{l}\text { White-back plus basal-white kernels } \\
\text { in Greenhouse }\end{array}$ & 12 & RM2197 & * & 0.01 \\
\hline & & Days to heading & 12 & RM2197 & $* *$ & 0.40 \\
\hline
\end{tabular}

1) Marker was linked to a QTL at significant $5 \%$ and $1 \%$ levels indicated by * and ${ }^{* *}$, respectively.

2) Additive effects ( $1 / 2$ weight) of Hana-echizen allele. Numbers in italics indicate additive effects based on arc sine transformation of the percentage of white-back and basal-white kernels.

respectively. Two QTLs for white-back kernels in the $\mathrm{F}_{3}$ population were detected on chromosomes 4 and 6 . The closest markers were RM3288 (chromosome 4) and RM3034, respectively. The QTLs near RM3034 were detected in both populations. The values of the phenotypic variance explained by the individual QTLs were 25.9\% (RM4512), $31.2 \%$ and $59.6 \%$ (RM3034), and 15.2\% (RM3288).

\section{Basal-white kernels}

Significant threshold LOD values $(\mathrm{P}<0.05)$ of basalwhite kernels in the $F_{2}$ population (2003) and in the $F_{3}$ population (2004) were 4.02 and 3.61, respectively. A QTL for basal-white kernels in the $F_{2}$ population was detected on chromosome 6. The closest marker to the QTL was RM3034. The phenotypic variance explained by the QTLs was $14.1 \%$. No QTLs for basal-white kernels were detected in the $\mathrm{F}_{3}$ population.

\section{White-back plus basal-white kernels in the greenhouse}

Significant threshold LOD value $(\mathrm{P}<0.05)$ of the white-back plus basal-white kernels under high temperature stress in the greenhouse in the $F_{3}$ population (2004) was 3.64. One QTL for white-back plus basal-white kernels in the greenhouse was detected on chromosome 6 . The closest marker to the QTL was RM3034. The phenotypic variance explained by the QTL was $75.1 \%$.

\section{Other traits}

Significant threshold LOD values $(\mathrm{P}<0.05)$ of days to heading in the $F_{2}$ population (2003) and $F_{3}$ population (2004) were 3.93 and 4.24, respectively. No QTLs for days to heading were detected in either the $\mathrm{F}_{2}$ or $\mathrm{F}_{3}$ population. Significant threshold LOD value $(\mathrm{P}<0.05)$ of one-thousand kernel weight in the $F_{2}$ population was 4.09. One QTL for one-thousand kernel weight was detected near RM4512 (chromosome 3). The phenotypic variance explained by the QTL was $12.3 \%$. Significant threshold LOD value $(\mathrm{P}<0.05)$ of panicle weight in the $F_{2}$ population was 4.38 . No QTLs for panicle weight were detected.

\section{Discussion}

Tolerance to kernel damage due to high temperature during the ripening period is one of the major objectives in rice breeding in Japan. Genetic and QTL information is necessary for efficient breeding, using DNA marker-assisted selection. Ebitani et al. (2005) identified three QTLs for the apparent quality of brown rice on chromosomes 2, 9 and 12, using chromosome segment substitution lines in which Kasalath (indica) segments had been introgressed into the Koshihikari (japonica) background. Terao et al. (2004) identified four QTLs for the apparent quality of brown rice on chromosomes 2, 4, 9 and 10 using a population derived from a cross between Habataki (indica) and Sasanishiki (japonica). He et al. (1999) found two QTLs for the percentage of white core kernels on chromosomes 8 and 12 using a doubled haploid population derived from a cross between ZYQ8 (indica) and JX17 (japonica). These are all the studies using a population derived from indicaljaponica crossings.

In the present study, QTLs for the apparent quality of brown rice were analyzed using a progeny population derived from a cross between two japonica varieties, Hanaechizen and Niigatawase. The apparent quality of brown rice was evaluated based on the percentage of white-back and basal-white kernels. Hana-echizen showed a very low percentage of white-back and basal-white kernels under paddy field conditions. The occurrence of white-back and basalwhite kernels in Hana-echizen was significantly lower than that in Niigatawase not only under low and high temperature conditions in paddy fields but also under high temperature stress in the greenhouse. Under the high temperature stress in the greenhouse, the percentage of white-back plus basalwhite kernels in Hana-echizen was about 30\% lower than that in Niigatawase. On the other hand, the values of panicle weight and one-thousand kernel weight in Hana-echizen were significantly higher than those in Niigatawase. In general, a larger sink size, namely higher value of panicle weight or one-thousand kernel weight, is more unfavorable 
for starch accumulation. For example, one-thousand kernel weight and the occurrence of white-back and basal-white kernels were positively correlated (Table 2 ). In this regard, the tolerance of Hana-echizen to kernel damage due to high temperature stress was very unique. Although the sink size of Hana-echizen was larger, the apparent quality of brown rice was much higer than that of Niigatawase.

We identified several QTLs for the apparent quality of brown rice. A putative QTL identified near the RM3034 marker on the short arm of chromosome 6 contributed most to the apparent quality of brown rice. This QTL was detected for white-back kernels, basal-white kernels and white-back plus basal-white kernels under greenhouse conditions. For the white-back kernels, QTLs were detected under both low temperature conditions in paddy fields in the $F_{2}$ population (2003) and under high temperature conditions in paddy fields in the $\mathrm{F}_{3}$ population (2004). For the basal-white kernels, a QTL was detected only in the $F_{2}$ population (2003). These QTLs near the RM3034 marker displayed high LOD scores (6.80-13.39) and relatively high phenotypic variations $(14.1 \%-75.1 \%)$, as shown in Table 3.

Based on these results, it appears that a gene with a major effect on the short arm of chromosome 6 controls the apparent quality of brown rice. Near the RM3034 marker, QTLs for days to heading or sink size (one-thousand kernel weight or panicle weight) were not identified in the present study. Therefore, the influence of days to heading or sink size on the apparent quality of brown rice was considered to be limited.

On the short arm of chromosome 6, several QTLs associated with chalkiness had been detected, according to other studies. Chalkiness is the visual rating of the chalky proportion in the grain. This trait is considerably affected by genes and also by the environment, especially high temperature immediately after heading. Li et al. (2003) reported the presence of a QTL associated with chalkiness of the endosperm on the short arm of chromosome 6 using an $\mathrm{F}_{2}$ population derived from the cross Nipponbare (japonica)/Kasalath (indica)//Nipponbare. Xu et al. (2000) also reported the presence of a QTL associated with chalkiness of the endosperm and the percentage of occurrence of white-core on the short arm of chromosome 6 , using $\mathrm{F}_{2}$ and $\mathrm{F}_{3}$ populations and an $\mathrm{F}_{10}$ recombinant inbred line population from a cross between Zh97 and Ming63, the parents of Shanyou63, the most widely grown indica hybrid rice variety in China. Shirasawa et al. (2006) also detected a QTL for white-back kernels under high temperature stress on the short arm of chromosome 6 using recombinant inbred lines derived from a cross between Kokoromachi (japonica) and Tohoku168 (japonica). The phenotypic variation was the largest among the QTLs they found. It is interesting to note that QTLs for the apparent quality of brown rice were detected on the short arm of chromosome 6, though mapping populations differed from each other. Due to the lack of common DNA marker shared in their and our studies, it is not possible to determine the allelism of these QTLs.
The putative QTL associated with white-back kernels was detected near the RM4512 marker on chromosome 3 under low temperature conditions in paddy fields in the $F_{2}$ population (2003). This QTL was not identified under high temperature conditions in paddy fields in the $\mathrm{F}_{3}$ population (2004) and the LOD score and phenotypic variation were smaller than those of the QTL near the RM3034 marker. Therefore, this QTL is likely to exert a minor effect on the apparent quality of brown rice, or it may act only under low temperature conditions (this QTL would not be effective under high temperature conditions such as those in 2004). Li et al. (2003) also reported the presence of a QTL associated with chalkiness of the endosperm on chromosome 3 . Due to the lack of common DNA marker shared in their and our studies, it is not possible to determine the allelism of these QTLs. Near the RM4512 marker on chromosome 3, a putative QTL for one-thousand kernel weight was also detected. The percentage of white-back or basal-white kernels was positively correlated with one-thousand kernel weight (Table 2). Therefore, further studies should be carried out to determine whether this QTL for the apparent quality of brown rice actually exists, or represents a side-effect of the QTL for one-thousand kernel weight.

The putative QTL associated with white-back kernels under high temperature conditions in paddy fields in the $\mathrm{F}_{3}$ population (2004) was detected near the RM3288 marker on chromosome 4. This QTL was not identified under low temperature conditions in paddy fields in the $F_{2}$ population (2003). Therefore, it is likely to exert a minor effect on the apparent quality of brown rice, or it may act only under high temperature conditions. On chromosome 4, we found only two polymorphic SSR markers. Further studies using a larger number of markers should be carried out.

Single marker analysis enabled to identify markers which were linked to QTLs (Table 4), namely RM3440 on chromosome 1, RM5654 on chromosome 2, RM552 on chromosome 11 and RM2197 on chromosome 12 were associated with QTLs for white-back or basal-white kernels. The QTLs for days to heading were linked to the RM2197 marker on chromosome 12 both in the $F_{2}$ and $F_{3}$ populations based on the single marker analysis. Further studies should be conducted in these regions where the genetic map is incomplete.

The QTLs detected in the present study represent the minimum number among the possible QTLs, because the genetic map is not complete and shows many gaps across the chromosomes. However the QTL information obtained in the present study should be useful for marker-assisted selection to breed varieties with a high apparent quality of brown rice, especially varieties with tolerance to kernel damage due to high temperature stress during the ripening period. The temperature during the ripening period in 2003 was lower than that in a normal year in Fukui. However, the QTL information obtained in the $\mathrm{F}_{2}$ population grown in 2003 could be used for DNA marker selection for high apparent quality of brown rice. As the temperature during the ripening period in 
paddy fields in 2004 was considered to correspond to high temperature stress, the QTL information obtained in the $F_{3}$ population grown in paddy fields in 2004 sould be useful to develop DNA markers to select varieties tolerant to kernel damage due to high temperature. The QTL information obtained in the $\mathrm{F}_{3}$ population grown in the greenhouse in 2004 could be important when grobal warming intensifies.

To use marker-assisted selection in a rice breeding program for tolerance to kernel damage due to high temperature stress, it will be necessary to identify DNA markers tightly linked to the genes controlling the tolerance by fine mapping. The development of near-isogenic lines differing only in the presence of a single and specific QTL for white-back or basal-white kernels should be prometed to perform fine mapping. We are currently constructing a genetic map by adding SSR and single nucleotide polymorphism markers to fill in the gap regions, and analyzing QTLs for the apparent quality of brown rice again, using recombinant inbred lines derived from the $\mathrm{F}_{3}$ lines to confirm the existence of the QTLs detected in the present study. In addition, backcrosses to develop near-isogenic lines have been initiated.

\section{Literature Cited}

Arisaka,M. (2001) The actual state of and the approaches to reduce the deterioration of brown rice quality in Niigata prefecture. Hokuriku Crop Sci. 36: 103-105.

Bao,G., A.Kobayashi and K.Tomita (2004) Mapping of quantitative trait loci controlling quality of brown rice. Breed. Res. 6 (Suppl. 1): 237.

Ebitani,T., Y.Yamamoto, M.Yano and M.Funane (2005) Analysis of quantitative trait loci for grain appearance, Kasalath alleles increase ratio of whole grains against Koshihikari, in rice. Jpn. J. Crop Sci. 74 (Extra issue 2): 290-291.

He,P., S.G.Li, Q.Qian, Y.Q.Ma, J.Z.Li, W.M.Wang, Y.Chen and L.H.Zhu (1999) Genetic analysis of rice grain quality. Theor. Appl. Genet. 98: 502-508.

Horiuchi,H., S.Mizuno, N.Nakagawa, K.Terada, K.Tomita, I.Ikeda, K.Aoki, T.Minobe, M.Tanoi, B.Ishikawa and T.Fukuda (1992) Breeding process and characteristics of a new variety "Hanaechizen". Hokuriku Crop Sci. 27: 1-4.

Hoshi,T., S.Abe, K.Ishizaki, H.Kasaneyama, K.Kobayashi, K.Hirao, T.Matsui, S.Azuma, K.Higuchi, T.Tamura, Y.Asai, K.Nakajima, A. Harada, M. Ozeki, Y.Sasaki, N. Abe, T. Kondo and H.Kanayama (2002) A new rice cultivar "Koshi-ibuki" by using of new selection methods of eating and grain quality. $\mathrm{J}$. of the Niigata Agric. Res. Inst. 5: 21-33.

Hoshikawa,K. (1989) The growing rice plant. Rural Culture Association, Tokyo. 296 p.

Iida,Y., T.Kirihara and T.Suga (1997) Varietal difference of the occurrence of white-ridge kernels under high temperature during ripening period in rice. Jpn. J. Crop Sci. 66 (Extra issue 1): 94-95.

Iida, Y., K.Yokota, T.Kirihara and R.Suga (2002) Comparison of the occurrence of kernel damage in rice plants grown in a heated greenhouse and in a paddy field of high temperature year. Jpn. J. Crop Sci. 71: 174-177.

Iida, Y. and M.Tabata (2003) Possibility of the breeding of rice varieties having high tolerance to kernel damage due to high temperature. A case of the rice breeding station in Ibaraki prefecture.
Jpn. J. Crop Sci. 72 (Extra issue 2): 452-455.

Inoue,K. (1999) Analytical studies on the dry matter production during the ripening period in relation to grain quality and palatability among the early-maturing rice cultivars. II. Effect of increasing rate of grain weight and nitrogen absorption on apparent quality and palatability. Hokuriku Crop Sci. 34: 27-29.

Kasaneyama,H., K.Itoh, S.Abe, K.Kobayashi, K.Hirao, T.Matui and T.Hoshi (1999) Improvement of grain and eating quality for rice breeding in Niigata prefecture. XVI. Test of ripening ability at hot water irrigation in rice plant. Hokuriku Crop Sci. 34: 21-23.

Komaki,Y., H.Ohta, K.Fukui and Y.Uehara (2000) Varietal difference in quality of brown rice as influenced by high temperature during ripening period. Hokuriku Crop Sci. 35: 10-12.

Konno,S., T.Konta, Y.Nakayama, H.Miyano, H.Miura, H.Takatori and T.Hayasaka (1991) Effect of growth and environmental conditions during the grain filling period on ripening, grain yield and quality of paddy rice. Bull. Yamagata Agric. Exp. Stn. 25: 7-22.

Kumura,A. (1995) Physiology of high-yielding rice plants from the viewpoint of dry matter production and its partitioning. In "Science of the rice plant, volume two: physiology" Matsuo, T. et al. (eds.), Rural Culture Association, Tokyo. p. 704-766.

Lander, E.S., P. Green, J.Abrahamson, A. Barlow, M.J. Daly, S.E. Lincoln and L.Newburg (1987) MAPMAKER: an interactive computer package for constructing primary genetic linkage maps of experimental and natural populations. Genomics 1: 174-181.

Li,Z.F., J.M.Wang, J.F.Xia and H.Q.Zhai (2003) Mapping quantitative trait loci underlying appearance quality of rice grains (Oryza sativa L.). Acta Genetica Sinica 30: 251-259.

Monna,L., N.Kitazawa, R.Yoshino, J.Suzuki, H.Masuda, Y.Maehara, M.Tanji, M.Sato, S.Nasu and Y.Minobe (2002) Positional cloning of rice semidwarfing gene, $s d-1$ : rice "green revolution gene" encodes a mutant enzyme involved in gibberellin synthesis. DNA Res. 9: 11-17.

Morita,S. (2000) Effects of high air temperature on ripening in rice plants. Analysis of ripening performance under climate conditions by changing in cropping seasons and/or transferring pots from lowland to upland. Jpn. J. Crop Sci. 69: 400-405.

Nagahata,H. and K. Yamamoto (2005) Evaluation of high temperature ripening ability using the temperature gradient chamber. Breed. Res. 7: 95-101.

Nagato,K., M.Ebata and Y.Kono (1961) On the adaptability of rice varieties to high temperature in the ripening periods. Jpn. J. Crop Sci. 29: 337-340.

Nagato,K. and M.Ebata (1965) Effects of high temperature during ripening period on the development and the quality of rice kernels. Jpn. J. Crop Sci.34: 59-66.

Nishimura, N., R.Kaji and T.Ogawa (2000) Varietal difference in the occurrence of coarse grain due to the high temperature stress given during the ripening period of rice plants. Breed. Res. 2: 17-22.

Omoteno,M., Y.Kojima, T.Ebitani, T.Yamaguchi, N.Mukaino and Y.Yamamoto (2003) Analysis of factors producing white-based and white-backed rice under the weather condition in 2001. Hokuriku Crop Sci. 38: 15-17.

Sasaki, Y., Y.Imai and H.Hosokawa (1983) Studies on prevention of qualitative deterioration of rice grains produced at high temperature. J. of the Niigata Agric. Exp. Stn. 33: 45-54.

Shirasawa,K., K.Sasaki, K.Nagano, S.Kishitani and T.Nishio (2006) 
QTL analysis of high-temperature-stress tolerance in filling period based on rice grain quality. Breed. Res. 8 (Suppl. 1): 155.

Tabata,M., Y.Iida and R.Ohsawa (2005) Genetic analysis of occurrence of white-back rice and basal-white rice associated with high temperature during the ripening period of rice. Breed. Res. 7: 9-15.

Taira,H. (1995) Physicochemical properties and quality of rice grains. In "Science of the rice plant, volume two: physiology" Matsuo, T. et al. (eds.), Rural Culture Association, Tokyo. $1064-1068 \mathrm{p}$.

Terao,T., M.Chiba, T.Hirose and O.Matsumura (2004) Quantitative trait loci for the quality of brown rice and their interaction to environmental factors. Jpn. J. Crop Sci. 73 (Extra issue 1): 9697.

Terashima,K. (2003) The effects of nationwide temperature increase on rice quality and the analysis of related factor. Jpn. J. Crop Sci. 72 (Extra issue 2): 446-451.

Terashima,K., Y.Saito, N.Sakai, T.Watanabe, T.Ogata and S.Akita (2001) Effects of high air temperature in summer of 1999 on ripening and grain quality of rice. Jpn. J. Crop Sci. 70: 449458.
Tsukimori,H. (2003) Effects of high temperature on the rice production and the technical countermeasures in Shimane prefecture. Jpn. J. Crop Sci. 72 (Extra issue 2): 434-439.

Wang, S., C.J.Basten and Z.B.Zeng (2006) Windows QTL Cartographer 2.5. Department of Statistics, North Carolina State University, Raleigh, NC. (http://statgen.ncsu.edu/qtlcart/ WQTLCart.htm)

Xu,C.G., S.B.Yu, Q.Zhang, J.X.Li, Y.Z.Xing and Y.F.Tan (2000) Genetic bases of appearance quality of rice grains in Shanyou 63, an elite rice hybrid. Theor. Appl. Genet. 101: 823-829.

Yamaguchi,T., T.Ebitani, H.Kaneda, Y.Kitani, Y.Ojima, M.Doi, T.shibashi, M. Mukaino, M. Omoteno, K. Takarada and Y.Yamamoto (2005) A new rice cultivar of early ripening, 'TEN-TAKAKU', with excellent grain appearance and eating quality under climatic fluctuations. Hokuriku Crop Sci. 41 (Extra issue): $53-54$.

Ye,S., A.Kobayashi and K.Tomita (2006) Analysis of quantitative trait loci associated with quality of brown rice. II Mapping of quantitative trait loci controlling white-back and basal-white kernels under high temperature condition. Breed. Res. 8 (Suppl. 1): 148 . 